\title{
Implications of event attribution for loss and damage policy
}

Article

Accepted Version

Parker, H. R., Cornforth, R., Boyd, E., James, R., Otto, F. E. L. and Allen, M. R. (2015) Implications of event attribution for loss and damage policy. Weather, 70 (9). pp. 268-273. ISSN 0043-1656 doi: https://doi.org/10.1002/wea.2542 Available at https://centaur.reading.ac.uk/40396/

It is advisable to refer to the publisher's version if you intend to cite from the work. See Guidance on citing.

To link to this article DOI: http://dx.doi.org/10.1002/wea.2542

Publisher: Royal Meteorological Society

All outputs in CentAUR are protected by Intellectual Property Rights law, including copyright law. Copyright and IPR is retained by the creators or other copyright holders. Terms and conditions for use of this material are defined in the End User Agreement.

\section{www.reading.ac.uk/centaur}

\section{CentAUR}

Central Archive at the University of Reading

Reading's research outputs online 


\title{
Implications of event attribution for loss and damage policy
}

Hannah R. Parker ${ }^{1 *}$, Rosalind J. Cornforth ${ }^{1}$, Emily Boyd ${ }^{2}$, Rachel James ${ }^{3}$, Friederike E. L. $\mathrm{Otto}^{3}$, Myles R. Allen ${ }^{3,4}$

${ }^{1}$ Department of Meteorology, University of Reading, Earley Gate, Reading RG6 6BB, UK ${ }^{2}$ Geography and Environmental Science, University of Reading, Whiteknights, Reading RG6 6AB, UK

${ }^{3}$ Environmental Change Institute, University of Oxford, South Parks Road, Oxford OX1

3QY, UK

${ }^{4}$ Department of Physics, University of Oxford, Parks Road, Oxford OX1 3PU, UK

*corresponding author: h.r.parker@pgr.reading.ac.uk

\begin{abstract}
$\underline{\text { Abstract }}$
The United Nations Framework Convention on Climate Change (UNFCCC) has established the Warsaw International Mechanism (WIM) to deal with loss and damage associated with climate change impacts, including extreme events, in developing countries. It is not yet known whether events will need to be attributed to anthropogenic climate change to be considered under the WIM. Attribution is possible for some extreme events- a climate model assessment can estimate how greenhouse gas emissions have affected the likelihood of their occurrence. Dialogue between scientists and stakeholders is required to establish whether, and how, this science could play a role in the WIM.
\end{abstract}

Key words: attribution, extreme weather, stakeholder, dialogue, loss and damage, UNFCCC, communication, WIM, Warsaw International Mechansim, United Nations Framework Convention on Climate Change 


\section{Introduction}

Extreme weather events are widespread across the globe. As an example, Figure 1 highlights the significant precipitation and temperature extremes that occurred just during the month of January 2015. The extremes identified in Figure 1 are those that were significant from a meteorological perspective. Many other events also occur which have important impacts on both human lives and livelihoods, and the biophysical environment, precipitating questions on their causes.. The climate system is changing and global average temperatures are increasing, and it has been shown that it is extremely likely that the majority of this warming over the last decades has been due to anthropogenic forcings (Bindoff et al., 2013). Yet how anthropogenic influences on the climate system are affecting extreme events is less well understood. How extreme events are changing, and could do in the future, is uncertain. How were the events in Figure 1 affected by human influence on the climate? What does this mean for the climate policies that aim to deal with their impacts?

Addressing the impacts of extreme weather events

Although the impacts of climate change and extreme events can be large in developed countries, people's livelihoods are much more vulnerable in developing countries (Cardona et $a l .$, 2012). Many African communities, for example, depend predominantly on rain-fed agriculture for their livelihoods, but have low resilience to extreme events as they are not prepared to cope with crises, and lack recovery time between recurrent crises (Cornforth et al., 2013). They lack timely, relevant and accessible weather and climate information to inform the decisions they need to make and on which to base coping strategies (Boyd et al., 2013). It is from this background that negotiations around the issues of 'loss and damage' due to climate change have emerged. These negotiations are occurring under the United Nations Framework Convention on Climate Change (UNFCCC).

Under the UNFCCC, countries debate how to address climate change (which it defines as changes attributable to human activity, rather than natural causes), including how to mitigate Greenhouse Gas (GHG) emissions and how to adapt to the impacts of a changing climate. This happens under the auspices of the annual Conference of the Parties (COP). The loss and damage concept was first discussed in the climate negotiations in 1991. Vanuatu, a small island in the South Pacific, proposed that small island developing states should receive compensation for the impacts of sea level rise they were experiencing (INC, 1991). They claimed that this sea level rise was driven by the GHGs emitted by developed countries, and called for developed countries to be held accountable. The proposition was rejected, but opened the door for further discussion and the establishment of a work programme on loss and damage in 2010 at COP16 in Cancun (UNFCCC, 2011). This was formalized at COP19 in Warsaw in 2013, through the Warsaw International Mechanism (WIM). The WIM aims specifically to help developing countries deal with loss and damage experienced due to the adverse effects of climate change (UNFCCC, 2013).

Clearly, an important step in this process is to better understand what the loss and damage concept actually encompasses. Whilst a formal definition is still pending, the UNFCCC have employed a number of working definitions (see for example UNFCCC, 2012b) for loss and damage. One such example states 'the actual and/or potential manifestation of impacts associated with climate change in developing countries that negatively affect human and natural systems' (see UNFCCC, 2012a). For others, a working definition relates to the residual impacts of climate change that are beyond adaptation. In a recent report presenting evidence of loss and damage by the United Nations University Institute for Environment and Human Security (UNU-EHS, Warner et al., 2012), loss and damage was defined as the 
'negative effects of climate variability and climate change that people have not been able to cope with or adapt to'.

Despite some lack of clarity over the concept, it has been agreed that the WIM will address the effects of both "slow-onset events" (such as sea level rise, glacial melting and ocean salinification) and "extreme events" (such as floods, droughts and heat waves) (UNFCCC, 2013) under its remit to deal with loss and damage due to climate change. This begs the question among climate scientists of whether events, both slow-onset and extreme, will have to be attributed to climate change, in order for their impacts to be considered under this mechanism. Will there need to be a demonstrable link between impacts on the ground and anthropogenic climate change before an event can be considered relevant? A link is likely to be easier to demonstrate for slow-onset events than for extreme events. The occurrences of slow-onset events in a changing climate are more predictable than extremes, with more established climate science providing evidence of their link to human influence (Bindoff et al., 2013). In contrast, there is much more uncertainty around how extreme events could be affected. The causal link is much harder to demonstrate. Is it reasonable to ask whether an extreme event was 'caused by' climate change?

In this discussion, we focus on emissions rather than other anthropogenic influences such as land degradation, which can also affect the climate.

\section{Attributing extreme weather events}

Climate scientists generally agree that it is difficult to attribute causality to a specific event. Extreme events can occur due to natural variations in the climate system, without human influence (Seneviratne et al., 2012), and so it is almost impossible to say that an extreme event would not have happened without anthropogenic climate change. However, it may be possible to make a demonstrable link between how the likelihood of a particular event occurring has changed and GHG emissions. Instead of attributing the occurrence of an event, it may be possible instead to attribute a change in risk.

Attributing the change in risk of extreme events to a changing climate is becoming possible using an emerging scientific technique called Probabilistic Event Attribution (PEA). The methodology was proposed by Allen (2003) as a tool to determine liability for damages caused by extreme events. PEA assesses how an external climate driver, such as anthropogenic GHG emissions, affects the likelihood of an event occurring. The technique requires large ensembles of climate model simulations which estimate two different worlds at the time of the event: one ensemble of the world as it was, and one of the world as it might have been had GHGs not been emitted. The likelihood of exceeding a precipitation or temperature threshold, for example, can be estimated for each of the two worlds using the simulations. The proportional change in likelihood of the event occurring can then be calculated. Results can help improve understanding of the climate system and the impacts of GHG emissions.

Stott et al. (2004) implemented the technique first in a study of the European summer heatwave of 2003. The study showed that human influence at least doubled the risk of a 2003-type heatwave, with $90 \%$ confidence. For the first time, PEA demonstrated a link between a regional weather event and anthropogenic climate change. In another similar study, Pall et al. (2011; see Fig. 2a) claimed that human influence had increased the risk of such events as the autumn 2000 flooding in England and Wales . In contrast, for other events, such as the spring 2001 flooding in England, the risk has decreased due to GHG emissions (Kay et $a l ., 2011$, see Figure 2b). Although for these examples, the changes in risk have been quantified, there are other events where it is simply not possible to assess how the likelihood 
has been changed, due to limitations of climate modelling. For an attribution statement to be robust, climate models must be able to reproduce the type of event under investigation, which is challenging for many events. This has impacted the widespread application of PEA as there can be substantial uncertainty in model outputs. The technique has thus mainly been used to study temperature and precipitation extremes, rather than applied to the attribution of individual weather systems, such as hurricanes. Substantially higher resolution climate models and significantly greater computing power would be required to be able to represent these systems.

The scientific studies that have used PEA have been conducted largely on an ad-hoc basis in the aftermath of events that have had devastating impacts on society, and primarily in developed countries. Not surprisingly, the media have recognized that linking events to climate change is of interest to the public and those affected (Boykoff, 2011). Increasing numbers of broadsheet articles are published following on from these PEA studies. A prime example if that of the Russian heatwave in 2010. Although the magnitude of the event could be explained by natural processes, PEA studies found that the likelihood of its occurrence had been increased by human activity (Dole et al., 2010, Otto et al., 2012, Rahmstorf and Coumou, 2011). This is illustrated in Figure 2c. The difference in temperature of the two scenarios is much smaller than the anomaly from the mean (vertical arrows) implying the magnitude could be natural, but the return time had increased threefold (horizontal arrow). The Guardian reported that "climate change increased [the] likelihood of [the] Russian heatwave" and that it was made "three times more likely" (Figure 3, Jha 2012). With regards to the recent extreme weather events that occurred in 2013, Jim Galvin commented recently in Weather: "Although there has been speculation, in particular in daily newspapers, that these events, especially the heavier rain and, perhaps, the related exceptionally low pressure of Typhoon Haiyan, are indicators of climate change, few such events have yet been attributed to anthropogenic effects on the atmosphere" (Galvin, 2014). Clearly there is an important role for dialogue between scientists and the media to ensure that correct and relevant information about such events is better communicated to the public.

A role for event attribution in climate policy?

Along with informing the public about extreme events, attribution results may be useful for international climate negotiations. If a demonstrable link between extreme events and climate change is required for the WIM, PEA will likely be a useful device in the UNFCCC "toolbox" -- to provide information on how anthropogenic influences to the climate system have altered the risk of certain extreme events occurring. This is particularly significant since questions of attribution of events have largely been neglected in loss and damage negotiations so far. Attribution is often linked to issues of liability and compensation, which are viewed as highly controversial in the UNFCCC process and so avoided by many (James et al. 2014). Developed countries do not want to be held accountable for loss and damage impacts and required to provide financial support to those affected. It was only by developing countries dropping demands for compensation in Warsaw that a loss and damage mechanism was established (McNamara, 2014).

Given these challenges, it is unclear whether attribution evidence will ever be required for the WIM and if so, what form that evidence should take, whether from PEA or otherwise. Arguably, attribution in terms of a change in risk might not ever constitute demonstrable evidence for those involved in the negotiations. What seems inevitable is that questions around the causality of extreme events will eventually come up in these discussions, even if they are being avoided currently (James et al., 2014), and that PEA may be able to support these discussions. There are of course factors other than climate change that also contribute to 
the impacts of extreme events. Hulme et al. (2011) argue that in using attribution when distributing funding, consideration would not be given to the vulnerability and development needs of communities. While there is clearly much more discussion to be had about the uses of PEA, in this article we look not to be prescriptive about its roles, but review the science in the context of the loss and damage negotiations.

In the meantime, there is an onus on scientists involved in attribution research to communicate clearly with potential stakeholders. As the WIM enters its development stage, there is a clear need for scientists to find out what the important questions are that policy makers are asking, and to help translate the science and convey its limitations. Without this communication, policy makers, and others involved with the UNFCCC loss and damage negotiations, are likely to stay disengaged with the science of PEA. The many differing perspectives on whether extreme events can be attributed to climate change from stakeholders engaged with loss and damage (Parker et al., 2015), will likely influence the role envisaged for attribution science in policy. For example, those who consider that all extreme events are caused by climate change may think that loss and damage from all extreme events should be addressed under the WIM. Those who think it is not possible to say anything about a single extreme event and its relation to a changing climate, may have different views about the conditions under which support should be given to those affected by an extreme event. Better communication between the groups will ensure that climate-related policy can be informed using the latest climate science.

\section{Communicating about event attribution science}

Dialogue between the climate scientists working in this research area and those involved in climate policy negotiations develops a strong basis for further collaboration (James et al., 2014) founded on a deeper understanding of user needs and scientific possibilities. This is important given recent concerns raised by some Non-Governmental Organisations (NGOs). They are concerned that a lack of scientific certainty in attribution results will hamper loss and damage negotiations, and policy makers may use this to avoid national responsibility. Cross-sector collaboration can expedite appropriate application of the latest available science to avoid further delays in dealing with the impacts of climate change (Parker et al., 2015).

There is also interest among stakeholders in deploying PEA studies to support a range of efforts, other than loss and damage. These include influencing high-level strategic policy making to encourage mitigation efforts and inform adaptation strategies (Parker et al., 2015), and helping the public and private sectors (e.g. insurance companies, legal bodies, and notfor-profit organizations (Stott and Walton, 2013)). PEA could benefit long-term development and poverty reduction by discouraging adaptation to events that have decreased in likelihood due to climate change, and are therefore expected to decrease in occurrence in the future (Stott et al., 2013). This may be especially important for communities with limited adaptation capacity and resources. Given these potential uses for attribution science, improved collaboration between scientists and policy makers working in different sectors is key. Different sectors will likely require different types of information (Stott and Walton, 2013) and scientists need to understand what these are to guide the ongoing development of attribution science.

In an effort to draw together event attribution methodologies and studies, annual reports in BAMS are now produced of attribution studies of various events of the previous year (e.g. Herring et al., 2014). Policy makers outside of the scientific community, are beginning to recognize their value (Herring et al., 2014) and increasing efforts are being made to foster two-way dialogue between scientists and stakeholders (Stott and Walton, 2013). Although 
such approaches are a good starting point, boundary organisations (such as the Africa Climate Exchange (AfClix), which works to ensure relevant climate science is available for policy decisions in Africa) will likely be required to further facilitate dialogue across the sciencepolicy interface. These can help ensure two-way communication begins and continues in a way that is valuable to all those involved.

\section{Conclusions}

With the WIM in its early stages of development and no formal definition of loss and damage in place, many questions remain about the role attribution science might play in future. One such question is whether a link to anthropogenic climate change is necessary for loss and damage to be considered under the UNFCCC mechanism, or whether loss and damage from any weather events will be eligible for support. There are also a number of practical considerations regarding the use of PEA. Should there be limits on the scale of events considered by an operational PEA system? And if so, how and who would decide these limits? Another consideration is whether a minimum threshold of changed risk would be required for an event to pass a legal 'test' and blame apportioned, whilst recognising other factors which may have affected the observed loss and damage. The use of PEA in a loss and damage mechanism will also raise ethical issues. For example, will the lure of compensation for events attributed to anthropogenic climate change become a disincentive to adapt?

Given this growing array of questions, now is the time to open the floor for discussions about PEA. Scientists, policy makers, humanitarian and development practitioners and others involved in loss and damage issues on the ground need to come together to examine what the science can provide and how this can match their needs (Parker et al., 2015). This will not only open dialogue around this emergent area, but also inform its future development so that research outputs are more relevant to users. In addition, it is important that in the wider climate policy context, the quality of communication between scientists and policy makers is improved and supported. Loss and damage is just one such small area where there are emerging links between what science can provide and what may be needed for effective climate-related policy. Given the growing number of activities creating dialogue spaces for scientists, policy makers and practitioners, we can be optimistic that loss and damage policy will be supported on the basis of need, by the latest attribution scientific research. 
$\underline{\text { References }}$

Allen MR. 2003. Liability for climate change. Nature 421: 891-892.

Bindoff NL, Stott PA, AchutaRao KM, et al. 2013. Detection and Attribution of Climate Change: from Global to Regional. In: Climate Change 2013: The Physical Science Basis. Contribution of Working Group I to the Fifth Assessment Report of the Intergovernmental Panel on Climate Change. [Stocker TF, Qin D, Plattner G-K, Tignor M, Allen SK, Boschung J, Nauels A, Xia Y, Bex V, Midgley PM (eds.)] Cambridge University Press, Cambridge, United Kingdom and New York, NY.

Boyd E, Cornforth RJ, Lamb PJ, et al. 2013. Building resilience to face recurring environmental crisis in African Sahel. Nature Climate Change 3, 631-637.

Boykoff, M. 2011. Who speaks for the climate?: making sense of media reporting on climate change. Cambridge University Press, Cambridge, UK

Cardona OD, van Aalst MK, Birkmann J, et al. 2012 Determinants of risk: exposure and vulnerability. In: Managing the Risks of Extreme Events and Disasters to Advance Climate Change Adaptation. A Special Report of Working Groups I and II of the Intergovernmental Panel on Climate Change. [Field CB, Barros V, Stocker TF, Qin D, Dokken DJ, Ebi KL, Mastrandrea MD, Mach KJ, Plattner G-K, Allen SK, Tignor M, Midgley PM (eds.)]. Cambridge University Press, Cambridge, UK, and New York, NY, USA, pp. 65-108.

Cornforth, R. J., Lamb, P. J. and Boyd, E. 2013. Watching the Rains to Build Resilience in the African Sahel. Edited by Rosamund Southgate and Virginia Murray, 2013 Report of the UNISDR Scientific and Technical Advisory Committee (April 4, 2013).

Dole R, Hoerling M, Perlwitz J, et al. 2011. Was there a basis for anticipating the 2010 Russian heat wave? Geophys. Res. Lett., 38: L06702.

Galvin JFP. 2014. Editorial: The weather of 2013. Weather, 69: 287.

Herring SC, Hoerling MP, Peterson TC, Stott PA (Eds.). 2014. Explaining Extreme Events of 2013 from a Climate Perspective. Bull. Amer. Meteor. Soc., 95: S1-S96.

Hulme M, O’Neill SJ, Dessai S. 2011. Is Weather Event Attribution Necessary for Adaptation Funding? Science, 334: 764-765.

INC. 1991. Vanuatu: Draft Annex Relating to Article 23 (Insurance) for Inclusion in the Revised Single Text on Elements Relating to Mechanisms (A/AC.237/WG.II/Misc.13) Submitted by the Co-chairmen of Working Group II Available at $<$ http://unfecc.int/resource/docs/a/wg2crp08.pdf $>$

James R, Otto F, Parker H, et al. 2014. Characterizing loss and damage from climate change. Nature Climate Change, 4: 938-939.

Jha A. 2012. Climate change increased likelihood of Russian 2010 heatwave - study. Guardian [online] 21 February. Available at < http://www.theguardian.com/environment/ 2012/feb/21/climate-change-russian-heatwave $>$

Kay AL, Crooks SM, Pall P, Stone DA. 2011. Attribution of Autumn/Winter 2000 flood risk in England to anthropogenic climate change: A catchment-based study. J. Hydrol., 406: 97112. 
McNamara, KE. 2014. Exploring loss and damage at the international climate change talks. Int. J. Disaster Risk Sci., 5: 242-246

Pall P, Aina T, Stone D, et al. 2011. Anthropogenic greenhouse gas contribution to flood risk in England and Wales in autumn 2000. Nature, 470: 382-385.

Parker H, Boyd E, Cornforth R, et al. 2015. Do loss and damage negotiations need event attribution science? Climate Policy. In review.

Otto FEL, Massey N, vanOldenborgh GJ, et al. 2012. Reconciling two approaches to attribution of the 2010 Russian heat wave. Geophys. Res. Lett., 39: L04702.

Rahmstorf S, Coumou D. 2011. Increase of extreme events in a warming world. Proc. Natl. Acad. Sci. U. S. A., 108: 17905-17909.

Seneviratne SI, Nicholls N, Easterling D, et al. 2012. Changes in climate extremes and their impacts on the natural physical environment. In: Managing the Risks of Extreme Events and Disasters to Advance Climate Change Adaptation. A Special Report of Working Groups I and II of the Intergovernmental Panel on Climate Change. [Field CB, Barros V, Stocker TF, Qin D, Dokken DJ, Ebi KL, Mastrandrea MD, Mach KJ, Plattner G-K, Allen SK, Tignor M, Midgley PM (eds.)]. Cambridge University Press, Cambridge, UK, and New York, NY, USA, pp. 109-230.

Stott PA, Allen M, Christidis N, et al. 2013. Attribution of weather and climate-related extreme events. In: Hurrell, J.W. and Asrar, G.R. (Eds.) Climate science for serving society: research, modeling and prediction priorities, Springer: Dordrecht.

Stott PA, Stone DA, Allen MR. 2004. Human contribution to the European heatwave of 2003. Nature 432: 610-614.

Stott PA, Walton P. 2013. Attribution of climate-related events: understanding stakeholder needs. Weather, 68: 274-279.

UNFCCC. 2011. Report of the Conference of the Parties on its Sixteenth Session, Held in Cancun from 29 November to 10 December 2010 FCCC/CP/2010/7/A.1 Available at $<$ http://unfccc.int/resource/docs/2010/cop16/eng/07a01.pdf $>$

UNFCCC. 2012a. A literature review on the topics in the context of thematic area 2 of the work programme on loss and damage: a range of approaches to address loss and damage associated with the adverse effects of climate change FCCC/SBI/2012/INF.14 Available at $<$ http://unfccc.int/resource/docs/2012/sbi/eng/inf14.pdf $>$

UNFCCC. 2012b. Current knowledge on relevant methodologies and data requirements as well as lessons learned and gaps identified at different levels, in assessing the risk of loss and damage associated with the adverse effects of climate change FCCC/TP/2012/1 Available at $<$ http://unfccc.int/resource/docs/2012/tp/01.pdf $>$

UNFCCC. 2013. Decision 2/CP.19: Warsaw International Mechanism for Loss and Damage Associated with Climate Change Impacts FCCC/CP/2013/10/Add.1 Available at $<$ http://unfccc.int/resource/docs/2013/cop19/eng/10a01.pdf\#page $=6>$

Warner K, van der Geest K, Kreft S, et al. 2012. Evidence from the frontlines of climate change: Loss and damage to communities despite coping and adaptation. Loss and Damage in Vulnerable Countries Initiative. Policy Report. Report No. 9. Bonn: United Nations University Institute for Environment and Human Security (UNU-EHS). 
Figures

Figure 1 Climate events January 2015. Were any of these events caused by climate change? Source: National Climatic Data Center Asheville, NC (2015)

\section{Figure 2}

Return times for precipitation-induced floods aggregated over England and Wales for (a) conditions corresponding to September to November 2000 with boundary conditions as observed (blue) and under a range of simulations of the conditions that would have obtained in the absence of anthropogenic greenhouse warming over the 20th century (green) with different Atmosphere-Only General Circulation Models (AOGCMs) used to define the greenhouse signal, black horizontal line corresponds to the threshold exceeded in autumn 2000 (from Pall et al., 2011); (b) corresponding to January to March 2001 with boundary conditions as observed (blue) and under a range of simulations of the condition that would have obtained in the absence of anthropogenic greenhouse warming over the 20th century (green) adapted from Kay et al. (2011); (c) return periods of temperature-geopotential height conditions in the model simulations for the 1960s (green) and the 2000s (blue). The vertical black arrow shows the anomaly of the 2010 Russian heat wave (black horizontal line) compared to the July mean temperatures of the 1960s (dashed line). The vertical red arrow gives the increase in temperature for the event whereas the horizontal red arrow shows the change in the return period (from Otto et al., 2012). Source: Bindoff et al. (2013)

Figure 3 The Guardian report on the attribution studies of the 2010 Russian heatwave. Source: Guardian News \& Media Ltd (2012) 